has always been a matter of dispute owing to the differences in colour, which fall into three phaseswhite, grey and dark. The author follows Schiøler and other Danish ornithologists, and divides the forms in Greenland into two races, Falco $r$. candicans, the white bird breeding in the north, and $F$. r. obsoletus, breeding in the sub-Arctic and low Arctic zones, and which may be either grey or dark in colour with many intermediate coloured birds.

Among the passeres, the field-fare calls for attention, since it first began to nest in Greenland in 1943 and is now a regular breeder; this is an interesting case of colonization. From the systematic list at the end of this part we learn that 224 species and subspecies have been recorded from Greenland, and, out of these, 64 breed regularly, 58 have only occurred once and most of the remainder are casual visitors.

There are a very good bibliography and map. It is to bo hoped that Dr. Salomonsen will see his way to bring out in the near future a cheaper and smaller edition, without plates, of this important fauna.

N. B. KINNEAR

\section{LIFE OF THE WESTERN ATLANTIC COAST}

\section{The Living Tide}

By N. J. Berrill. Pp. xi+256+16 plates. (London: Victor Gollancz, Ltd., 1951.) 16s. 6d. net.

$\mathrm{P}$ OF. N. J. BERRILL'S excellent contribution to the ever-growing number of popular books about life in the sea is concerned mainly with the inshore life of the east coast of the United States. There are occasional excursions elsewhere, particularly to Salcombe and the coasts of Cornwallscenes of the author's youth-but for the most part the theme is distinctly North American, though quite a number of the species described are common to both sides of the Atlantic. From Loggerhead Key in the Dry 'Tortugas northwards to Maine a number of outstanding examples of the marine flora and fauna are described with a bare minimum of technical words. The writing, never dull, presents a depth of sound biological knowledge in a light and entertaining manner that is wholly delightful. Especially noteworthy are the accounts of the breeding of the turtle, of the upside-down jellyfish Cassiopeia in the moat of Fort Jefferson, of Limulus, and of the skull and breeding of the crucifix fish (a species of cat-fish). There are first-rate chapters devoted to the lobsters, squids and seals of Maine.

It is a pity that Prof. Berrill, in his endeavour to eliminate all technicalities, leaves the biologist on the eastern side of the Atlantic to puzzle out the identity of some of the animals he mentions. There is need for an appendix giving the scientific equivalents of such popular appellations as the sea potato, the grey snapper, the blue crab, the quahog and the soft.shelled clam. The last-named, we are assured, is "sand-gaper" in an English fish-market. 'There are occasional lapses of style, as in the sentence about the fanning feet of the barnacle pulling in a handful of water and food; and there are occasional errors of fact, as in the statement that Zostera is a terrestrial grass which has invaded the sea. But to dwell on these rare slips would be to give a false impression of a most readable and accurately written book.

Compared with the text, the photographic illustrations are disappointing. Two of the pictures are from habitat groups in the New York Natural History Museum; but the fanciful captions may lead the unwary to assume that they are photographs from life (unless, indeed, the wires suspending the trigger-fish happen to be noticed). The remaining photographs are from life and are of very mixed quality. The best, a good one, is of living squids; a few photographs are not in proper focus and should not have been included.

D. P. WILSON

\section{THE SUGARCANE}

\section{Botany of Sugarcane}

By Dr. C. van Dillewijn. Pp. xxiii + 37I. (Waltham, Mass. : Chronica Botanica Co., 1952.) n.p.

$\mathrm{HE}$ author has produced this considerable volume for the best of reasons, namely, that he wanted to do so and because he felt that such a volume, which relates to a major tropical crop, if not overdue, would certainly be timely. In contrast to other works on the sugarcane, which have been mainly practical, technological, historical or economic in their conception and outlook, this book is what its title declares it to be ! essentially a work of botany. In it, on the basis of a bibliography of some 617 titles, the author has produced an account of the sugarcane plant in all its phases of germination, growth, development and reproduction. As perhaps might be expected, the data available to the author are somewhat uneven: some aspects have been the subject of intensive research, while others have remained comparatively neglected, those aspects which stand in a close relation to agricultural or technological aspects being most amply documented. Thus photosynthesis occupies thirty-two pages, respiration less than four.

The first section is devoted to a detailed illustrated account of the morphology and anatomy of the stem, buds, leaves, inflorescence and roots, and the second to physiological aspects, including germination, tillering, growth, chemical composition, nutrition, water relations, photosynthesis and respiration. In a contemporary work it is perhaps surprising that the genetical and cytological aspects are not included, though a chapter is devoted to the evaluation of vegetative characters in the classification of varieties, while the part played by the introduction of new varieties in safeguarding the industry is fully recognized.

The author rightly considers that cane-growing should be treated as a science, and with due emphasis he directs attention to the fact that there is a great gap between the relatively low efficiency in the field and the high efficiency in the factory. This he attributes to lack of knowledge, to failure to make use of knowledge that is available, and to dependence on tradition, local opinion and empiricism rather than on knowledge of the botany of the sugarcane and the related principles of its cultivation. In the present volume an attempt is made to remedy these defects and to make available to workers in all countries a comprehensive work of reference. The author and his publishers are to be congratulated on their achievement, and the hope may perhaps be expressed that the Chronica Botanica Company will regard this present volume as but one of a series of monographs on the botany of important crop plants.

C. W. WARDLAW 